\title{
ESTUDO ARQUITETÔNICO DO CASARÃO DOS MARTINS E SUA RESPECTIVA IMPORTÂNCIA PARA PRESERVAÇÃO DA IDENTIDADE E MEMÓRIA DE MARTINÓPOLIS - SP
}

\author{
Lucas Loveira, Fabrícia Dias da Cunha de Moraes Fernandes Borges \\ Universidade do Oeste Paulista - UNOESTE, Faculdade de Engenharias e Arquitetura e Urbanismo, \\ Presidente Prudente, SP. E-mail: luc.loveira7@gmail.com
}

\section{RESUMO}

O presente trabalho apresenta a cidade de Martinópolis e a sua formação, demonstrando que o Casarão dos Martins é uma de suas primeiras construções, e por esta razão deveria receber uma maior atenção por ser uma peça fundamental para a preservação da memória e identidade da cidade. O principal objetivo deste estudo é discorrer brevemente sobre a história da formação da cidade de Martinópolis, apresentando o Casarão dos Martins e o seu estado de preservação encontrado nos dias atuais. Como metodologia foram utilizados levantamentos bibliográficos e levantamentos in loco através materializados em fotografias e uma catalogação das principais patologias do edifício. Por mim, com a realização deste trabalho conclui-se que a o Casarão dos Martins possui grande importância para a cidade, sendo um patrimônio histórico local e, por sua vez, deveria ser tombado para assim assegurar a preservação de materialidade.

Palavras - chave: Martinópolis, patrimônio histórico, memória, identidade, preservação.

\section{ARCHTECTURAL STUDY ABOUT MANSION OF MARTINS AND ITS RESPECTIVE IMPORTANCE FOR THE PRESERVATION OF MARTINÓPOLIS - SP INDENTIFY AND MEMORY}

\begin{abstract}
This paper presents the city of Martinópolis and its formation, demonstrating that the Manson of Martins is one of his first buildings, and therefore should receive more attention because it is a key player for the preservation of memory and identity of the city. The aim of this study is to briefly discuss the history of the formation of the city of Martinópolis, presenting the Mansion of the Martins and their state of preservation found today. The methodology we used literature surveys and surveys on site using materialized in photographs and a cataloging of the main pathologies of the building. For me, this work is concluded that the Mansion of Martins has great importance for the city, with a historic heritage and, in turn, should be overturned so as to ensure the preservation of materiality.

Key - words: Martinópolis, historic heritage, memory, identity, preservation.
\end{abstract}




\section{INTRODUÇÃO}

A cidade de Martinópolis - SP está localizada no Oeste Paulista, distando a uma distância de $491 \mathrm{~km}$ da capital do estado, a cidade de São Paulo -SP. A maior cidade localizada nos arredores de Martinópolis é Presidente Prudente, localizada a uma distância de $23 \mathrm{~km}$.

O desbravamento das terras onde esta situada a cidade aconteceu com o prolongamento dos trilhos da Estrada de Ferro Sorocabana em 1910, onde estava parada em Salto Grande esperando pela continuação do seu trajeto. A inauguração da estação José Teodoro aconteceu em 05 de agosto de 1917, que no começo era apenas um vagão de trem. A estação ficou isolada durante sete anos, onde continha em seu entorno apenas a guarita do guarda-chaves e as casas dos ferroviários. Em 1924 o imigrante português João Gomes Martins que tinha como trabalho a importação e exportação de secos e molhados em São Paulo começou a investir na colonização das terras. Nesta época ele comprou 10.000 alqueires da Fazenda Montalvão e preparou todo o terreno para ali começar o surgimento da cidade (DALTOZO, 1999).

No dia 20 de dezembro de 1929 o povoado se tornou Distrito de Paz, ainda recebendo o mesmo nome da estação ferroviária: José Teodoro. Em 1937 o fundador do povoado faleceu em São Paulo, porém o seu filho primogênito João Gomes Martins Filho continuou com o trabalho de colonização. Em 29 de janeiro de 1939 aconteceu a instalação solene do município de Martinópolis, recebendo este nome em homenagem ao seu colonizador. Em 13 de junho de 1945 foi instalada a Comarca de Martinópolis. Até 1940 o município possuía aproximadamente $4.000 \mathrm{~km}^{2}$, fazendo limite com as cidades de Regente Feijó, Presidente Prudente, Valparaíso, Guararapes, Tupã e Rancharia. Partes das cidades de Lucélia, Osvaldo Cruz, Sagres, Nantes e Pracinha foram originados de desmembramentos das terras do município de Martinópolis (DALTOZO, 1999).

Atualmente a cidade conta com aproximadamente 25.805 habitantes contando com uma extensão territorial de $1.253,564 \mathrm{~km}^{2}$ segundo o IBGE (2010). O objeto estudo deste trabalho é a antiga residência do fundador da cidade de Martinópolis, o Coronel João Gomes Martins, localizada na rua Carolina de Freitas Martins (Figura 01).

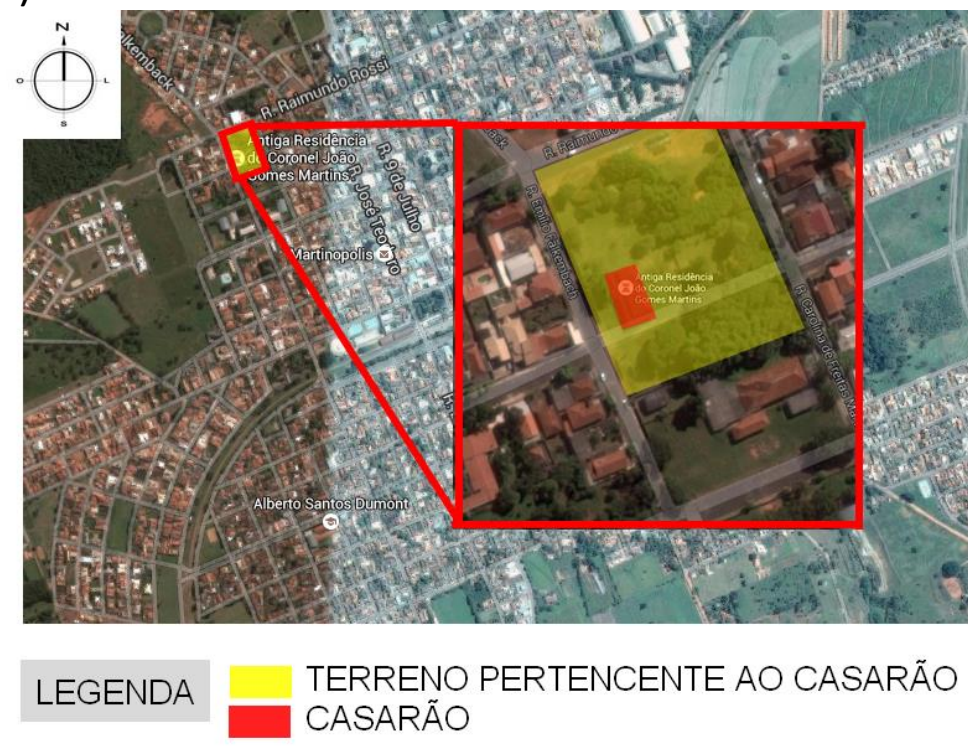

Figura 01. Localização do Casarão dos Martins

Fonte: Google Earth, 2016. Editado pelo autor, 2016. 
O Casarão que abrigou a família Martins por quase cem anos, construído pelo fundador da cidade Coronel João Gomes Martins, encontra-se em completo abandono nos dias atuais, sofrendo um constante processo de degradação por vândalos e as marcas do passar do tempo. Esta importante edificação que conta parte da história da cidade de Martinópolis- SP está totalmente esquecida, mesmo que esteja sob os cuidados do plano urbanístico diretor da cidade. É notória a sua importância para a preservação da identidade e memória da cidade, uma vez que foi uma das primeiras construções executadas no município e pertenceu a família fundadora.

\section{METODOLOGIA}

Este trabalho foi realizado através do estudo in loco do casarão dos Martins, realizando assim um levantamento de sua materialidade, além de uma pesquisa bibliográfica sobre a formação da cidade de Martinópolis e a importância histórica da edificação em questão.

\section{RESULTADOS}

A residência foi uma das primeiras edificações construídas na cidade. Sua construção é datada da década de 1930, possuindo grande importância para o entendimento do nascimento, crescimento e desenvolvimento da cidade. Com o falecimento do Coronel João Gomes Martins, a casa foi deixada de herança para os seus filhos João Gomes Martins Filho, que deu continuidade ao trabalho de seu pai e pouco usufruiu da residência, e Guiomar de Freitas Martins, sendo a única a residir na residência até 2009 quando adoeceu e teve que se mudar para perto de seus familiares (FOLHA DA CIDADE, ed. 359, Mar. 2010).

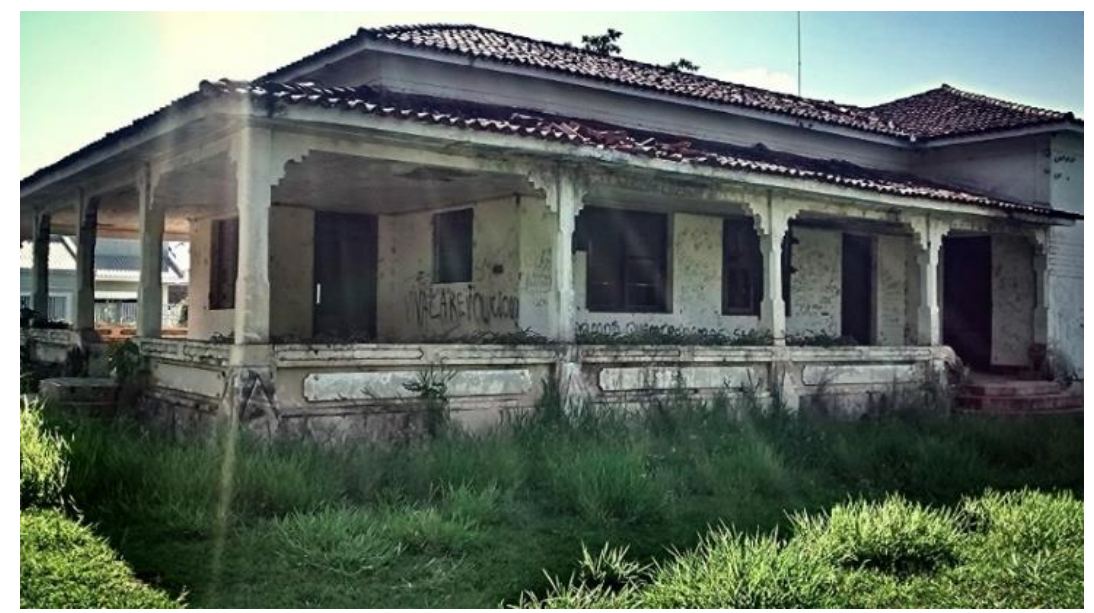

Figura 02. Antiga Residência do Coronel João Gomes Martins

Fonte: Acervo do autor, 2014.

A edificação, que ficou conhecida como Casarão dos Martins, era utilizada para encontros políticos e com comerciantes da época, pois o Coronel possuía a sede da Colonização Martins na capital. A área fica a poucos quarteirões do centro da cidade (FOLHA DA CIDADE, ed. 359, Mar. 2010).

Apesar do estado de degradação, o casarão não possui grandes alterações realizadas ao longo dos anos. A alteração mais significativa está no seu telhado (Figura 32) que foi modificado. A edificação ainda possui grande parte de suas características principais e, sem dúvidas, merece atenção por fazer parte da memória e identidade da cidade (FOLHA DA CIDADE, ed. 359, Mar. 2010).

A edificação possui características da arquitetura Neocolonial do Brasil. Este estilo arquitetônico foi um dos primeiros estilos brasileiros onde os arquitetos tomaram consciência das possibilidades do país de acordo com a sua originalidade, tendo uma grande importância refletida 
na arquitetura brasileira atual. Os maiores nomes deste movimento foram Ricardo Severo e Victor Dubugras, tendo como grande incentivador deste movimento também o crítico e historiador de arte José Mariano Filho. Dentre as características deste estilo pode-se citar as varandas sustentadas por colunas simples, telhados planos com largos beirais, muxarabis, azulejos que recobriam as paredes das varandas, balcões, entre outros (BRUAND, 2010).

A planta do Casarão é configurada em formato retangular com algumas reentrâncias que disponibilizam o acesso para a sala de estar, um hall que dá para um corredor de circulação e para a sala de jantar, esta última contendo um lance de escadas que segue em direção para a cozinha que está localizada no pavimento inferior juntamente com o depósito.

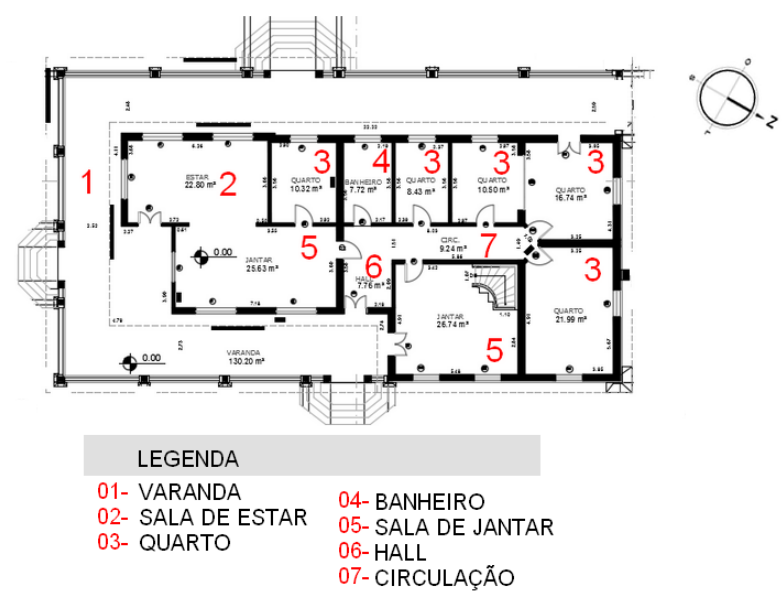

Figura 03. Planta baixa do pavimento térreo do casarão

Fonte: Acervo de Marcos Paulo da Silva, 2014. Editado pelo autor 2016.

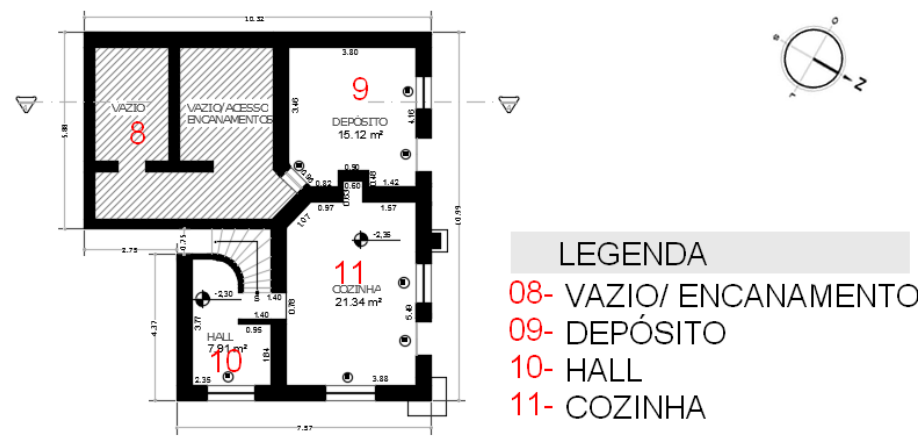

Figura 04. Planta baixa do pavimento térreo do casarão

Fonte: Acervo de Marcos Paulo da Silva, 2014. Editado pelo autor, 2016

É possível notar as marcas do tempo e da degradação que o edifício sofreu em toda a sua materialidade. Vândalos picharam, saquearam e danificaram a edificação depois que a última moradora, dona Guiomar Martins, se mudou do Casarão. $O$ edifício possui diversas aberturas que auxiliam na ventilação e iluminação. Todas as janelas são de madeira na parte externa no estilo veneziana, e por dentro possuem um fechamento em vidro, porém a maioria das janelas estão totalmente danificadas. 


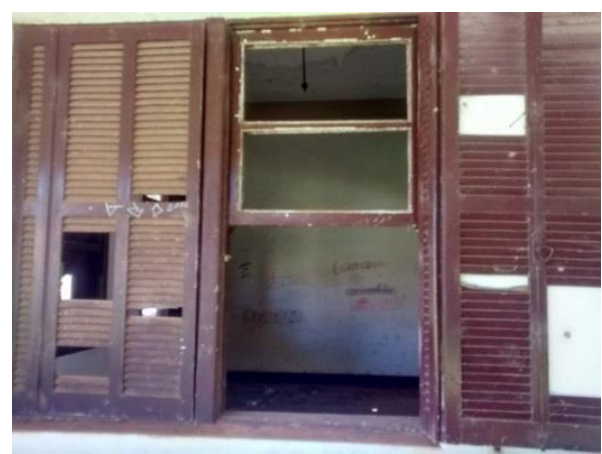

Figura 05. Janela danificada do Casarão Fonte: Acervo do autor, 2016.
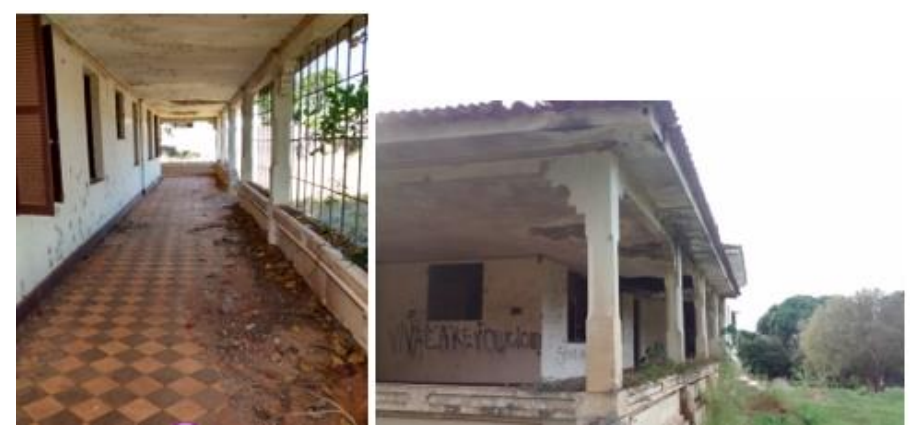

Figura 06. Varanda e pichações

Fonte: Acervo do autor, 2016.

Fica evidente que o edifício precisa passar por uma restauração o mais rápido possível, antes que desapareça e leve com ele um ícone da formação da memória e identidade da cidade de Martinópolis.

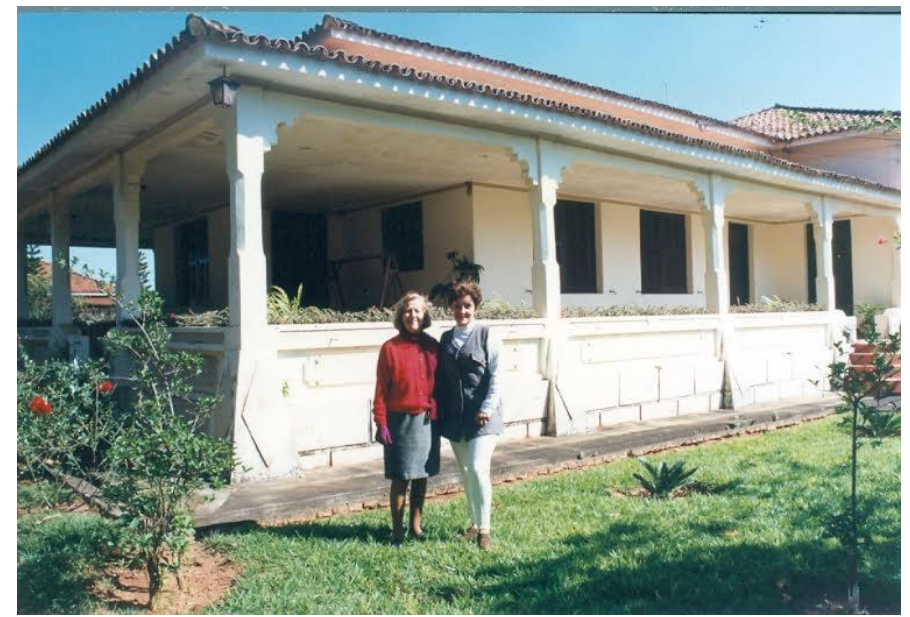

Figura 07. Casarão dos Martins no ano de 1996

Fonte: Acervo de José Carlos Daltozo, 2016. 


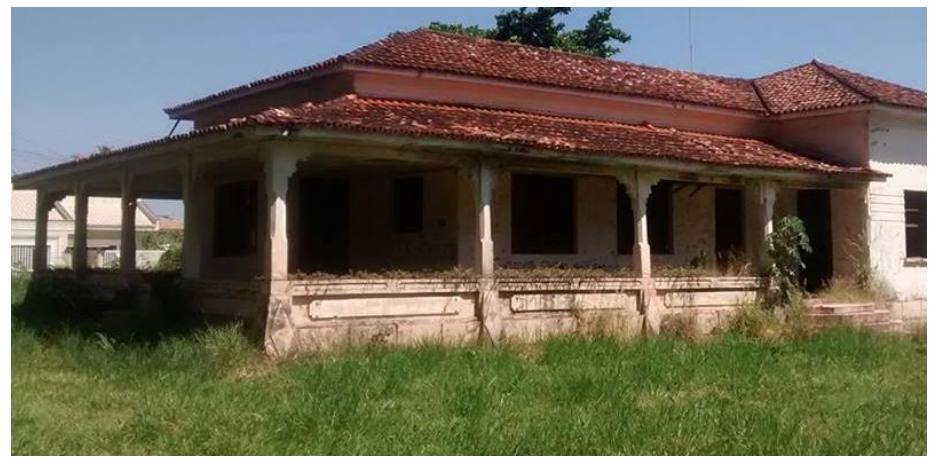

Figura 08. Casarão nos dias atuais

Fonte: Acervo do autor, 2016.

Além do Casarão dos Marins, no terreno estão situadas mais duas edificações datadas da mesma época. Estes blocos, sendo o Café Martinópolis e a Cozinha Auxiliar, também estão totalmente degradados, com partes do telhado faltando, rachaduras e outras diversas patologias.

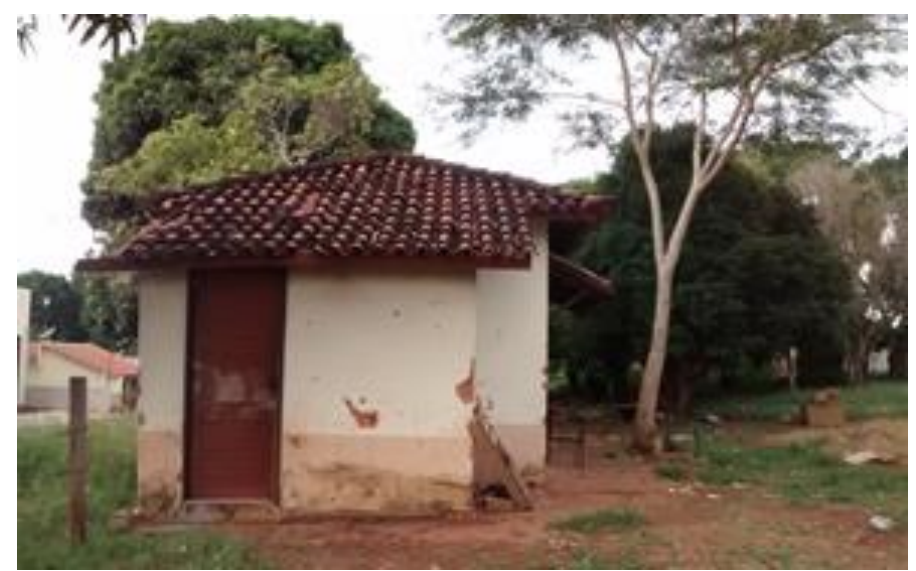

Figura 09. Fachada Oeste da Cozinha Auxiliar Fonte: Acervo do autor, 2016.

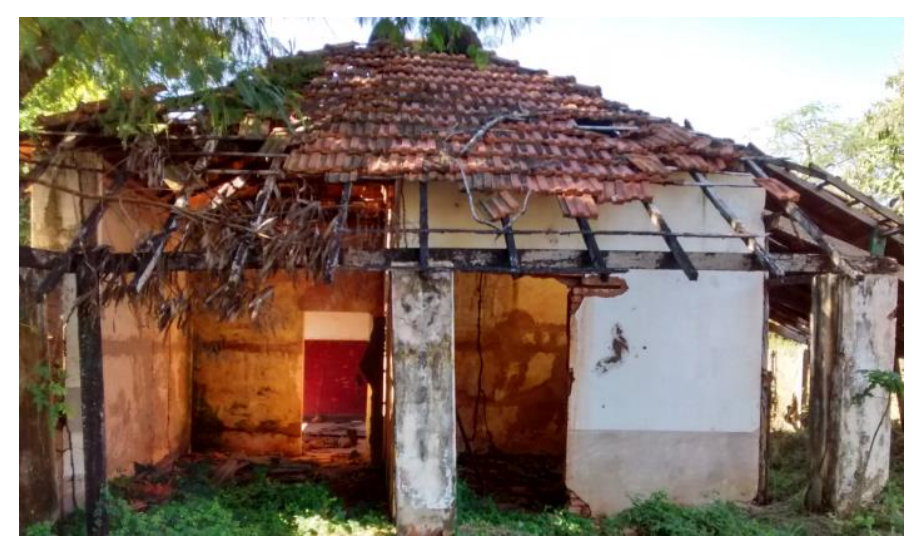

Figura10. Fachada Oeste do Café Martinópolis Fonte: Acervo do autor, 2016.

\section{CONCLUSÃO}

Diante das informações apresentadas neste artigo pode-se concluir que o Casarão dos Martins possui um grande significado na história da constituição da cidade de Martinópolis, pois pertenceu a família que fundou a cidade, que por consequência é destacada como uma das primeiras construções realizadas no município. Desta forma, a sua integridade física é agente 
importante para a propagação da história da cidade, assim como um grande agente de salvaguarda da memória e identidade local. Porém, nota-se que a edificação está em estado de degradação pelo descaso dos agentes públicos responsáveis pela sua preservação, e se nenhuma atitude for tomada a edificação pode vir a ruir. Uma conscientização da população e da prefeitura se faz necessária para proteger a materialidade e integridade física deste importante patrimônio histórico, que conta a história da cidade e seu desenvolvimento através de suas pátinas e sua representatividade singular.

\section{REFERÊNCIAS}

DALTOZO,J. Martinópolis. Sua história e sua gente. Martinópolis: Gráfica Martipel, 1999.

PATRIMÔNIO de Martinópolis vive momentos de tensão. Folha da Cidade, Martinópolis, 19 mar. 2010. P.9.

BRUAND,Y. Arquitetura contemporânea no Brasil. 5. e.d. São Paulo: Perspectiva, 2010. 